\title{
In situ measured cross section geometry of old timber structures and its influence on structural safety
}

\author{
Paulo B. Lourenço ${ }^{1}$, Hélder S. Sousa ${ }^{2}$, Ricardo D. Brites ${ }^{3}$, Luís C. Neves ${ }^{4}$
}

\begin{abstract}
${ }^{1}$ Professor, ISISE, Universidade do Minho - Dept. of Civil Engineering, Azurém, 4800-058 Guimarães, Portugal. e-mail: pbl@ civil.uminho.pt, Tel: +351 253510200

${ }^{2}$ PhD student, ISISE, Universidade do Minho - Dept. of Civil Engineering, Azurém, 4800058 Guimarães, Portugal, e-mail: hssousa@civil.uminho.pt, Tel: +351 253510200

${ }^{3} \mathrm{PhD}$ student, ISISE, Universidade do Minho - Dept. of Civil Engineering, Azurém, 4800058 Guimarães, Portugal, e-mail: rbrites@ civil.uminho.pt, Tel: +351 253510200

${ }^{4}$ Assistant professor, UNIC, UNL - Universidade Nova de Lisboa, Quinta da Torre, 2829516, Monte da Caparica, Portugal, e-mail: lacn@fct.unl.pt
\end{abstract}

\begin{abstract}
Old timber structures may show significant variation in the cross section geometry along the same element, as a result of both construction methods and deterioration. As consequence, the definition of the geometric parameters in situ may be both time consuming and costly. This work presents the results of inspections carried out in different timber structures. Based on the obtained results, different simplified geometric models are proposed in order to efficiently model the geometry variations found. Probabilistic modelling techniques are also used to define safety parameters of existing timber structures, when subjected to dead and live loads, namely self-weight and wind actions. The parameters of the models have been defined as probabilistic variables, and safety of a selected case study was assessed using the Monte Carlo simulation technique. Assuming a target reliability index, a model was defined for both the residual cross section and the time dependent deterioration evolution. As a consequence, it was possible to compute probabilities of failure and reliability indices, as well as, time evolution deterioration curves for this structure. The results obtained provide a proposal for definition of the cross section geometric parameters of existing timber structures with different levels of decay, using a simplified probabilistic geometry model and considering a remaining capacity factor for the decayed areas. This model can be used for assessing the safety of the structure at present and for predicting future performance.
\end{abstract}

KEYWORDS: timber structures, geometry models, structural reliability, biological decay 


\section{INTRODUCTION}

For centuries, wood has been used as a structural material. Nevertheless, timber structures with historical value can present significant deterioration and damage, limiting their use, requiring replacement or casting doubts on their structural safety. It is therefore fundamental to define methodologies to assess the present safety and to predict how safety will evolve in time.

In general, existing timber construction resorts to simple structural systems, even if complex systems such as intricate spatial trusses or old structures with multiple interventions also exist (Valle et al, 2005). In the case of typical roof truss systems, stresses can be calculated considering linear elastic analysis, based on finite element analysis or the displacement method, due to the simple nature of most timber structures and the quasi-brittle behaviour of timber in tension and unconfined shear (Smith, 1982). Although timber evidences a ductile behaviour in compression, bending failure for lower grade timber is usually brittle (JCSS, 2006) and brittle failure in flexural buckling has also been reported (Pettigrew et al., 2006). In modelling a timber structure, difficulties arise in the definition of the mechanical properties of the material since timber properties vary not only between members of the same structure but also within the same member. Complexity is increased by wood anisotropy and the influence of load duration and moisture content on the behaviour of timber. In existing timber structures, the geometry of the cross section is an important parameter for visual grading (UNI, 2004), since members with irregular cross section and large variability along their length may be found, especially for older structures (Brites, 2011), requiring time consuming in situ measurements. Finally, existing timber structures may also be deteriorated, leading to further difficulties in the assessment of the residual cross section geometry.

Visual grading techniques are globally uncertain and uneconomic (Kessel and Sandoz 1989; Sandoz 1991) and therefore methods to improve the efficiency of the measurements should be implemented. For these reasons, probabilistic methodologies have proved their interest in the analysis of existing structures as they allow the inclusion of uncertainty in the mechanical and geometrical properties. Although probabilistic methodologies are fairly well established for other materials, in timber structures further research is still necessary. In this field, the Joint Committee for Structural Safety Model Code (JCSS, 2006) presents a relevant contribution with the definition of a probabilistic framework for safety assessment of timber structures. Reliability analysis of timber structures requires three main steps: definition of resistance properties, definition of effects of actions and computation of the probability of failure or reliability index. A detailed discussion on the probabilistic modelling of timber structures can be found in Köhler (2007) and Köhler et al. (2007). Decay may also be modelled using probabilistic methods (Leicester, 2001; Wang et al., 2006), as predictions on decay evolution and its consequences on structural safety and maintenance planning may be considered using time evolution deterioration curves. The concept of life-cycle performance evaluation of deteriorating structures has been studied by several authors (Thoft-Christensen, 1998; Nowak et al., 1998; Frangopol et al., 2001; Kong and Frangopol, 2002; Neves and Frangopol, 2005) for concrete and steel structures, and it is possible to adapt the same 
conceptual framework for the life-cycle design of timber structures, provided that the uncertainties in the input variables are quantified (Frangopol et al., 1997).

The objectives of this paper are to evaluate the uncertainty of cross section geometric measurements in existing timber structures by providing actual in situ measurements of the cross sections geometry in old timber structures, to define different geometric models and to describe the use of complex and simplified probabilistic methodologies to analyze the safety of old timber structures. In this work, the safety of traditional timber structures is analyzed over their lifecycle, considering the effect of deterioration in a probabilistic framework using a bi-linear decay model (Leicester, 2001) and defining life-cycle performance in terms of the reliability index. The mechanical properties of timber structures are considered as random variables, as are the loads and the deterioration parameters. The proposed methodology is applied to a timber roof in Coimbra, Portugal, which presented significant deterioration due to biological attack and for which detailed inspections results are available. The resistance is modelled following Eurocode 5 (CEN, 2004), with the necessary adaptations for a probabilistic analysis. The models are calibrated considering the results of four inspected timber roofs in Portugal.

\section{SAFETY ASSESSMENT OF TIMBER STRUCTURES}

The fundamental properties for the safety assessment of timber trusses are the bending, compressive and tensile strength, and the modulus of elasticity. Probabilistic models for these parameters are proposed in the Joint Committee for Structural Safety Model Code (JCSS, 2006). The bending strength and the modulus of elasticity are defined as key parameters, and the model employed for these parameters must be defined considering the properties of the used timber. A lognormal distribution is proposed for the bending strength and modulus of elasticity, with coefficients of variation of $25 \%$ and $13 \%$, respectively. Considering the JCSS model code (JCSS, 2006), the other resistance properties of timber can be defined based on the key properties through the empirical expressions presented in Table 1, where $E$ is the expected value and $C o V$ is the coefficient of variation. The impact of load duration and moisture content can be modelled through a deterministic parameter, which in Eurocode 5 (CEN, 2004) is denoted by $k_{\text {mod }}$ and affects the resistance of the timber structure or elements. A more detailed analysis of full probabilistic approaches for determination of load duration factors is given in Sørensen et al. (2005). The loads considered here, for the case of structural analysis of timber roof structures, were the dead and wind loads. The dead load can be easily determined if the geometry of the structure is known to some degree of accuracy. This parameter can be characterized by a normal distribution, with mean equal to the nominal value (CEN, 2002). The coefficient of variation depends on the existing uncertainty on the geometry of the structure and weight of non-structural elements. A value of the coefficient of variation equal to $10 \%$ is usually assumed for timber structures (JCSS, 2001). The wind load can be modelled as a static uniformly distributed load. The intensity of this load depends on the location and geometry of the structure. A Gumbel distribution can be used to describe this load, and a coefficient of variation of $40 \%$ is often considered, if no regional information is 
available (Ranta-Maunus, 2004). The mean value of the wind load can be defined based on this assumption and the nominal values defined in Eurocode 1 (CEN, 2005).

Table 1: Relation between key properties (shaded) and other properties for timber mechanical properties, according to JCSS (2006).

\begin{tabular}{lccc}
\hline Property, X & Distribution & $E[\mathrm{X}]$ & $\operatorname{CoV}[\mathrm{X}]$ \\
\hline Bending strength, $f_{\mathrm{m}}$ & Lognormal & $E\left[f_{\mathrm{m}}\right]$ & 0.25 \\
Bending modulus of elasticity, $E_{\mathrm{m}}$ & Lognormal & $E\left[E_{\mathrm{m}}\right]$ & 0.13 \\
Density, $\rho_{\mathrm{m}}$ & Normal & $E\left[\rho_{\mathrm{m}}\right]$ & 0.10 \\
Tensile strength parallel to grain, $f_{\mathrm{t}, 0}$ & Lognormal & $0.6 E\left[f_{\mathrm{m}}\right]$ & $1.2 \operatorname{CoV}\left[f_{\mathrm{m}}\right]$ \\
MOE - tension parallel to grain, $E_{\mathrm{t}, 0}$ & Lognormal & $E\left[E_{\mathrm{m}}\right]$ & $\operatorname{CoV}\left[E_{\mathrm{m}}\right]$ \\
Compressive strength parallel to grain, $f_{\mathrm{c}, 0}$ & Lognormal & $5 E\left[f_{\mathrm{m}}\right]^{0.45}$ & $0.8 \operatorname{CoV}\left[f_{\mathrm{m}}\right]$ \\
Shear modulus, $G_{\mathrm{v}}$ & Lognormal & $E\left[E_{\mathrm{m}}\right] / 16$ & $\operatorname{CoV}\left[E_{\mathrm{m}}\right]$ \\
Shear strength, $f_{\mathrm{v}}$ & Lognormal & $0.2 E\left[f_{\mathrm{m}}\right]^{0.8}$ & $\operatorname{CoV}\left[f_{\mathrm{m}}\right]$ \\
\hline
\end{tabular}

\section{IN SITU GEOMETRIC MEASUREMENTS}

Geometric survey is required for the safety analysis of old timber structures. This survey must define global dimensions of the structure (such as span or elevation) and cross section dimensions of members (such as width and height). The definition of the cross section dimensions in old timber structures is complex, not only because round elements may be found but also because deterioration is present. The deterioration of timber structures in Southern Europe is mostly a consequence of the attack of xylophagous insects and wooddestroying fungi (Pinto-Lopes, 1950; Teles and Valle, 2001). These attacks cause a destruction of timber in the outer areas of the section, progressing into the interior.

Unlike the deterioration process in other materials, in timber the main effect of deterioration is a change in geometry, as the mechanical properties are usually not affected.

In order to obtain information for geometrical models of old timber structures a survey was conducted in four existing roof timber structures (Brites, 2011) from the Northern and Central regions of Portugal. For each roof, several measurements are taken along the timber elements with the help of a laser meter (range $30 \mathrm{~m}$, precision $5 \mathrm{~mm}$ ), a measuring tape (range $5 \mathrm{~m}$, precision $1 \mathrm{~mm}$ ) and a digital calliper (range $0.5 \mathrm{~m}$, precision $0.05 \mathrm{~mm}$ ). The geometrical characterization of the cross sections was made by measurement of the horizontal and vertical diameters $\left(\phi_{1}\right.$ and $\left.\phi_{2}\right)$ or height $(h)$ and width $(w)$ for circular and rectangular sections, respectively.

The considered structures include an old monastery roof from the $17^{\text {th }}$ century (Monastery of Arouca) and a late $18^{\text {th }}$ century roof of a university building (Chimico Laboratory, Coimbra). The most recent roof structures, built in the first half of the $20^{\text {th }}$ century, are from a church (St. Torcato's Sanctuary) and a palace (Ducal Palace of Bragança, Guimarães). All structures were built using chestnut (Castanea sativa Mill.) wood, with exception of the Chimico Laboratory where pine (Pinus canariensis Sweet) wood was used. Details on chestnut construction, very common in Northern Portugal, can be found in Feio et al. (2007) and Lourenço et al. (2007). 


\subsection{Monastery of Arouca}

The studied roof was built in the $17^{\text {th }}$ century and is composed by eight timber trusses with two parallel high tie beams, without any post, see Figure 1a. The trusses and the ridge beam have round cross sections and non-straight axis, while the purlins are more recent and present rectangular cross sections and straight axis. The results of the measurements are presented in Table 2, where $E$ is the average dimension and $C o V$ is the coefficient of variation. It is noted that the deterioration of the rafters is often asymmetric due to localized water infiltrations or different neighbouring bodies to the roof under consideration. For this reason, the north and south rafters are considered in independent groups. The results indicate that the coefficients of variation of the dimensions of the round cross section are much larger than the coefficients of variation of the rectangular cross sections (11\% on average for the purlins vs. $17 \%$ on average for the rest of the members). The lower tie beam has a larger coefficient of variation because the ends have a lower cross section than the central part of the element. The coefficient of variation of the purlins is within the expected range according to JCSS (2001).

\subsection{Chimico Laboratory, Coimbra}

This roof was built between 1773 and 1775, and the building was used as a chemical laboratory and classroom until 1998. The survey focuses on the roof of Wing 1, which was heavily deteriorated due to wood-boring beetles and fungi attack. It is assumed that the roof trusses are original, even if there are later additions and strengthening. The roof structure is composed by four trusses with an iron tie at the base and a timber tie beam at mid-height, see Figure 1b, where the post and braces are connected. The added strengthening elements (only in two of the trusses) are also shown in the figure under the rafters. The date of this intervention is not known but the wood is in better condition. The results from the geometrical survey (Table 2) indicate that the severe biological degradation provides very large coefficients of variation for the rafters and tie beam, particularly along the height of the members. The average coefficient of variation of the dimensions in these members is $18 \%$, whereas the average coefficient of variation for the height alone is $25 \%$. For the post and braces, the average coefficient of variation of the dimensions is $5 \%$.

\subsection{Ducal Palace of Bragança, Guimarães}

The roof was reconstructed in the 1930s and consists of two rafters with a spacing of $0.55 \mathrm{~m}$, on top of which timber sheeting with $0.015 \mathrm{~m}$ thickness and an asphalt sheet membrane for waterproofing were placed. The rafters are stabilized in the transverse direction by a ridge beam and two purlins on each slope. In addition, one high tie-beam, one steel tie at the bottom and one steel post are placed every $4.0 \mathrm{~m}$, as shown in Figure 1c. The axis of the members is straight and the structure is in very good overall condition, since a regular maintenance plan is in place. Table 2 shows that the average coefficient of variation is very low (about 5\%).

\subsection{Sanctuary of St. Torcato}

This three pitched roof structure was completed only in the 1940s and is, composed by four king post trusses with the addition of a higher tie beam at approximately mid-height of the post, see Figure 1d. The distance between the trusses varies between 4.1 and $6.4 \mathrm{~m}$ and these are the only surveyed trusses in which the connections are made by steel plates, bolts and 
nails. Table 2 shows that it is a recent structure, in good condition, and the average coefficient of variation is very low (about 3\%).

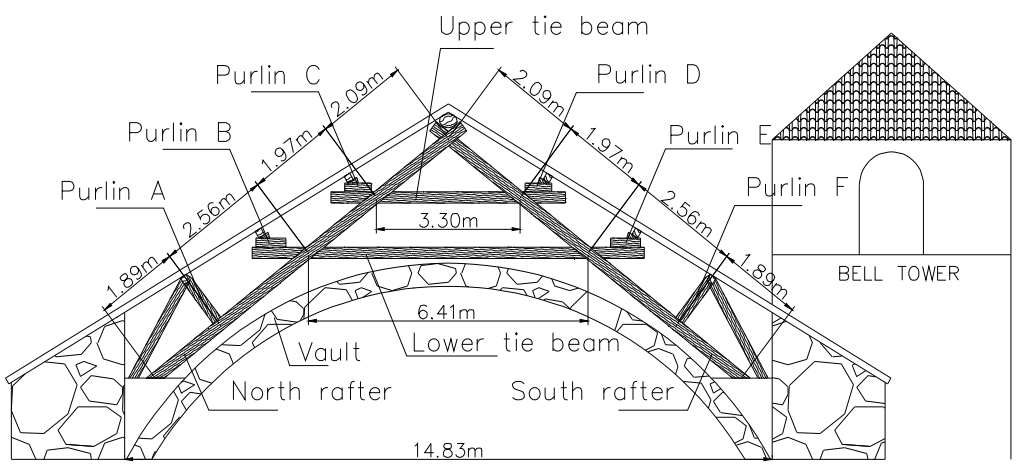

a)

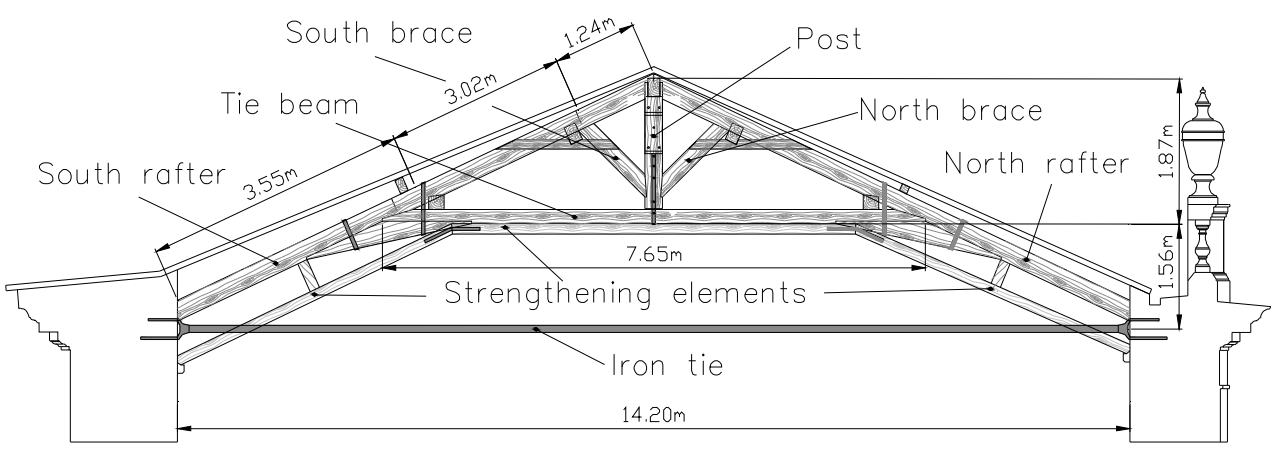

b)

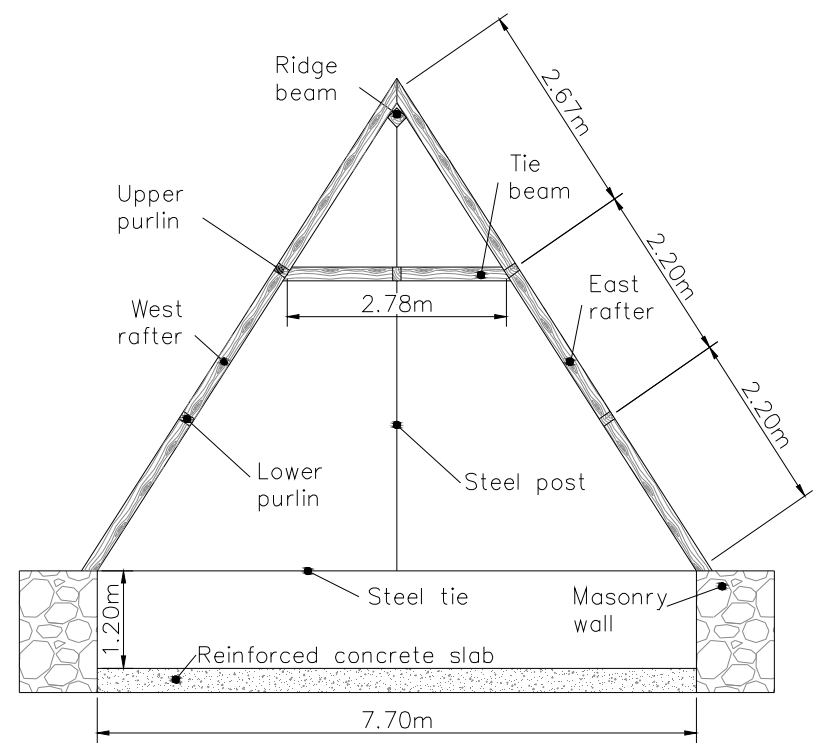

c) 


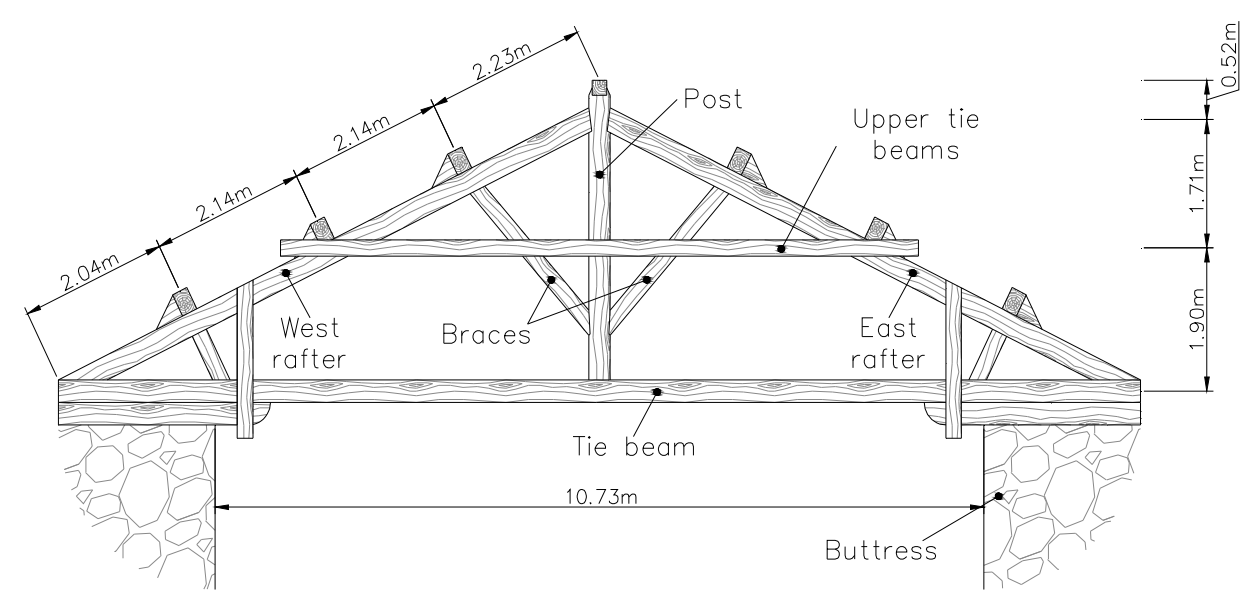

d)

Figure 1: Surveyed roof structures in Portugal, designation and average size of members: a) Monastery of Arouca; b) Chimico Laboratory; c) Ducal Palace of Bragança; d) Sanctuary of St. Torcato

\subsection{Comparison}

Even if the sample is small (Figure 2), it seems that structures built using rectangular sections (i.e. up to about 100 years old) and presenting very low biological deterioration, have coefficients of variation on the cross section dimensions close to 5\% (maximum found was about $10 \%$ ). For the older timber structures studied, deterioration plays a major role, resulting in a significant increase in uncertainty. For round timber elements with moderate to low biological deterioration, the coefficient of variation of about $15 \%$ seems to be applicable (maximum found was about 20\%). For highly deteriorated timber structures, a value of $20 \%$ or higher for the coefficient of variation might be applicable (maximum found was about $40 \%)$.

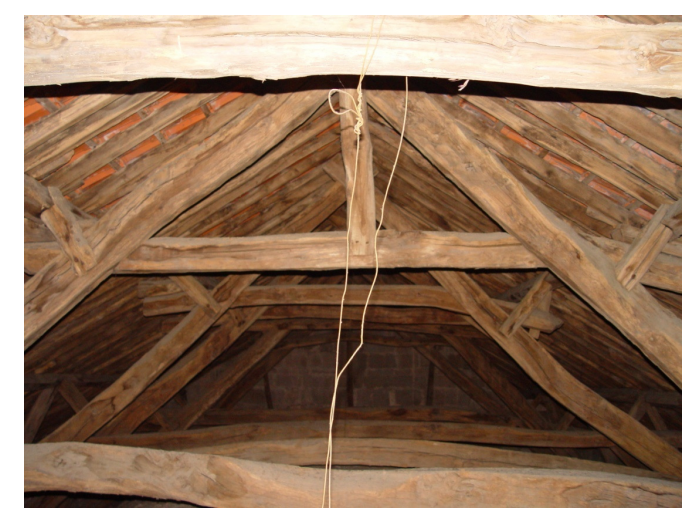

a)

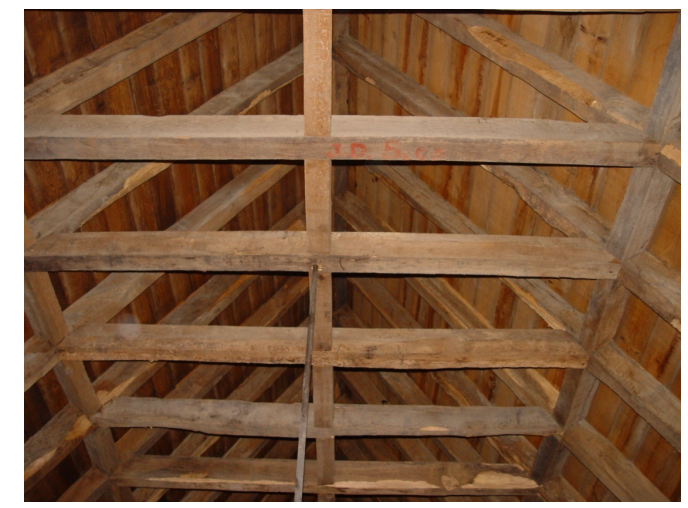

b)

Figure 2: Examples of existing timber roof structures: a) pre-industrialization with round cross sections, Arouca Monastery; b) post-industrialization with rectangular cross sections, Ducal Palace of Bragança 
Table 2: Statistical study of cross sections from geometrical survey.

\begin{tabular}{|c|c|c|c|c|c|c|c|}
\hline Member & Dimension & $E[\mathrm{~m}]$ & $\operatorname{CoV}[\%]$ & Member & Dimension & $E[\mathrm{~m}]$ & $\operatorname{CoV}[\%]$ \\
\hline \multicolumn{4}{|c|}{ Arouca's Monastery $\left(17^{\text {th }}\right.$ century $)$} & \multicolumn{4}{|c|}{ Ducal Palace of Bragança (20 $0^{\text {th }}$ century) } \\
\hline \multirow{2}{*}{ South rafter } & $\phi_{1}$ & 0.220 & 17.8 & \multirow{2}{*}{ East rafter } & $w$ & 0.111 & 7.9 \\
\hline & $\phi_{2}$ & 0.265 & 16.3 & & $h$ & 0.175 & 4.9 \\
\hline \multirow{2}{*}{ North rafter } & $\phi_{1}$ & 0.237 & 16.6 & \multirow{2}{*}{ West rafter } & $w$ & 0.110 & 4.9 \\
\hline & $\phi_{2}$ & 0.264 & 16.5 & & $h$ & 0.174 & 6.7 \\
\hline \multirow{2}{*}{ Upper tie beam } & $\phi_{1}$ & 0.217 & 13.8 & \multirow{2}{*}{ Tie beam } & $w$ & 0.109 & 3.8 \\
\hline & $\phi_{2}$ & 0.214 & 16.4 & & $h$ & 0.174 & 3.2 \\
\hline \multirow{2}{*}{ Lower tie beam } & $\phi_{1}$ & 0.222 & 19.3 & \multirow{2}{*}{ Purlins } & $w$ & 0.109 & 6.1 \\
\hline & $\phi_{2}$ & 0.231 & 20.2 & & $h$ & 0.170 & 5.5 \\
\hline \multirow{2}{*}{ Purlins } & $w$ & 0.139 & 11.7 & & & & \\
\hline & $h$ & 0.142 & 11.2 & \multicolumn{4}{|c|}{ St. Torcato's Sanctuary (20 ${ }^{\text {th }}$ century) } \\
\hline & & & & \multirow{2}{*}{ East rafter } & $w$ & 0.130 & 4.7 \\
\hline \multicolumn{4}{|c|}{ Chimico Laboratory ( $18^{\text {th }}$ century) } & & $h$ & 0.288 & 3.4 \\
\hline \multirow{2}{*}{ South rafter } & $w$ & 0.188 & 13.7 & \multirow{2}{*}{ West rafter } & $w$ & 0.131 & 3.4 \\
\hline & $h$ & 0.240 & 23.1 & & $h$ & 0.291 & 3.7 \\
\hline \multirow{2}{*}{ North rafter } & $w$ & 0.191 & 13.4 & \multirow{2}{*}{ Tie beam } & $w$ & 0.148 & 1.9 \\
\hline & $h$ & 0.255 & 18.6 & & $h$ & 0.304 & 4.3 \\
\hline \multirow{2}{*}{ Tie beam } & $w$ & 0.197 & 3.0 & \multirow{2}{*}{ Post } & $w$ & 0.120 & 0.8 \\
\hline & $h$ & 0.187 & 35.5 & & $h$ & 0.281 & 0.4 \\
\hline \multirow{2}{*}{ Post } & $w$ & 0.193 & 2.8 & \multirow{2}{*}{ East brace } & $w$ & 0.121 & 0.7 \\
\hline & $h$ & 0.263 & 5.1 & & $h$ & 0.225 & 0.3 \\
\hline \multirow{6}{*}{ Braces } & $w$ & 0.189 & 4.7 & \multirow{2}{*}{ West brace } & $w$ & 0.125 & 0.6 \\
\hline & $h$ & 0.207 & 6.1 & & $h$ & 0.224 & 6.1 \\
\hline & & & & \multirow{2}{*}{ S. upper tie beam } & $w$ & 0.102 & 1.0 \\
\hline & & & & & $h$ & 0.227 & 2.1 \\
\hline & & & & \multirow{2}{*}{ N. upper tie beam } & $w$ & 0.098 & 1.3 \\
\hline & & & & & $h$ & 0.223 & 2.0 \\
\hline
\end{tabular}


In the particular case of chestnut in Portugal, it can be stated that structures exhibit very low deterioration even after 70 years in service, and that after a few hundred years in service only moderate deterioration can be found. For the analyzed softwood structure, after about 200 years of service, the level of safety was totally unacceptable.

Finally, it is noted that detailed modelling of spatial varying geometry is complex and time consuming, above all due to the level of detail required during inspection of the structure. The question remains if the usage of average values or the lack of consideration of the spatial variation provides adequate levels of safety. For this reason, a set of simplified geometry models are used and compared in this paper, with the objective of defining a simple but accurate geometry modelling procedure for deteriorated timber structures.

\section{PROBABILISTIC MODELLING OF A TRUSS AND THE INFLUENCE OF CROSS SECTION GEOMETRY}

The Chimico laboratory introduced above will now be used as a case study for the discussion on the influence of the cross section geometry on the safety of existing timber structures, because: (a) extensive data was gathered during the inspections and non-destructive tests carried out for the four timber trusses (Valle et al, 2005); (b) there is a high level of deterioration making the safety assessment much more complex.

\subsection{Review of survey and damage characterization at Chimico laboratory}

Roof A1 from the laboratory is three pitched, including four trusses with a span of $14.2 \mathrm{~m}$, see Figure 3. As a consequence of the large deterioration and damage, the trusses were brought down and a detailed survey of the condition was made. In order to identify and locate the damage during the inspection, a detailed inspection was considered for each timber member (rafters, tie-beam, braces, post and wedges) of each truss, using traditional and advanced techniques, namely controlled drilling Resistograph to obtain density profiles (Rinn and Schweingruber, 1996) and impact hammer Pilodyn for surface fungi deterioration measurement (Görlacher, 1987). To calibrate these methods, tests in areas that apparently were in good condition were carried out as reference. The combination of the above techniques allowed the definition of deterioration and damage maps, see Figure 4 . The four trusses were in poor condition and, based on the inspection only, it was concluded that they were unfit for use without extensive repair and strengthening. 


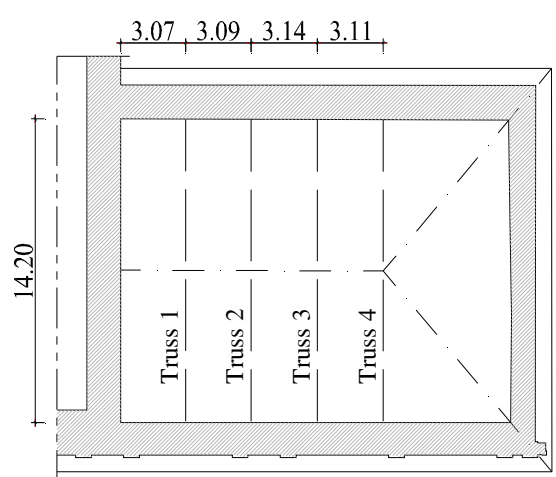

a)

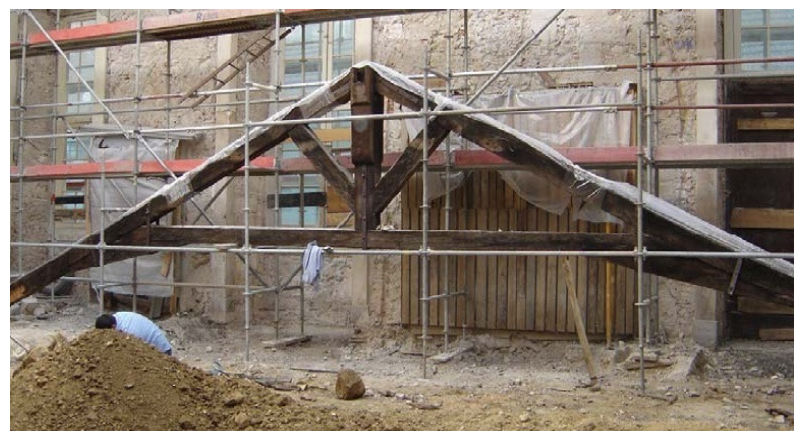

b)

Figure 3: Wing 1 from Chimico laboratory: (a) plan with location of trusses; (b) photograph of truss \#4 once it was moved down

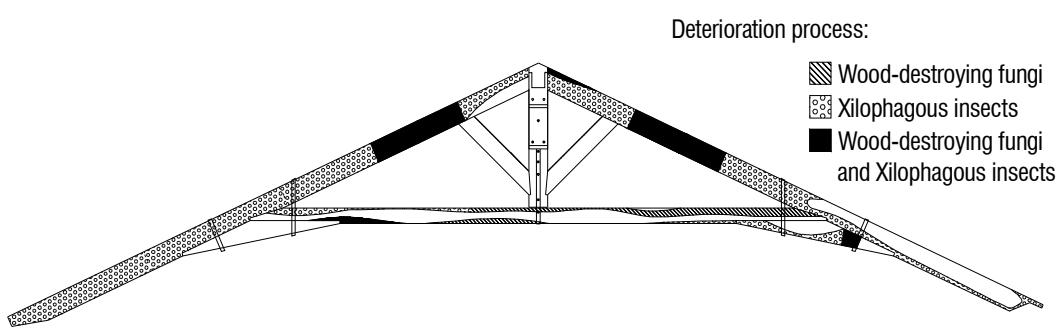

a)

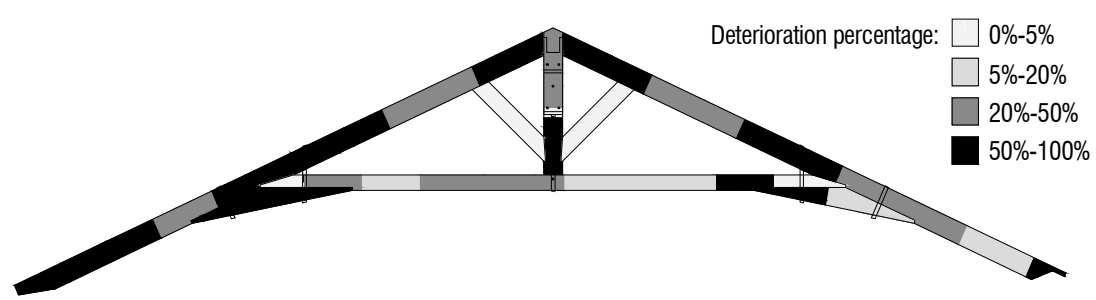

b)

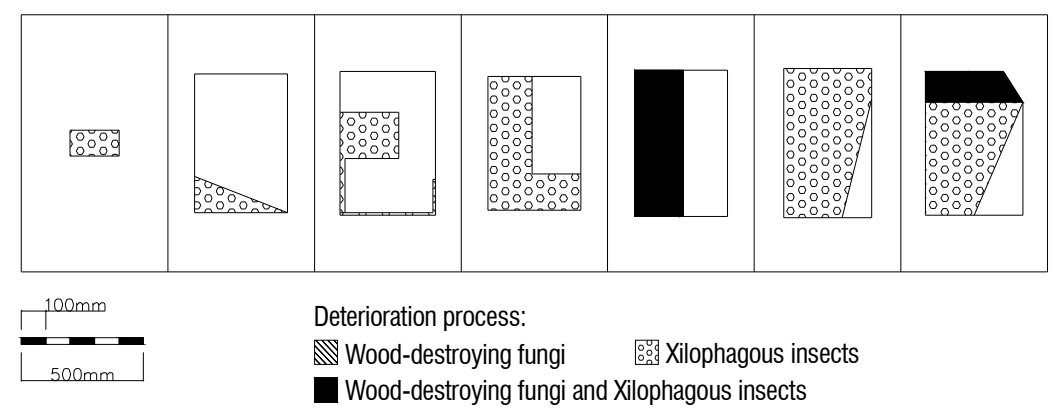

c)

Figure 4: Results obtained for each truss (truss \#1 is shown): a) deterioration and damage map; b) percentage of deterioration in terms of cross section; c) detailed information along a member about deterioration and damage. 


\subsection{Structural modelling and load definition}

The timber trusses were modelled as two-dimensional plane frames and for each element (tie beam, rafters, braces and post) a double hinged linear element was considered. Since the lower ends of the rafters were connected in situ by a metallic tie, it was considered that the horizontal and vertical displacements were restricted at these supports.

The material properties and the loads were defined as random variables. The bending strength was defined by a lognormal distribution with expected value of $25 \mathrm{~N} / \mathrm{mm}^{2}$ and a coefficient of variation of $25 \%$. For the modulus of elasticity a lognormal distribution was assumed with expected value $12 \mathrm{kN} / \mathrm{mm}^{2}$ and a coefficient of variation of $13 \%$. The expected values for the random variables were considered from (IPQ, 1995), while the coefficients of variation and probabilistic density functions were chosen according to the recommendations in JCSS (2006).

In order to define the cross section geometry, four models were assumed taking into consideration the results of the survey and assuming that the area affected by biological agents offered no contribution to resistance (Figure 5). The existing strengthening of two of the trusses is not included in the analysis, as the objective here is to discuss the usage of different geometric models and not to provide an accurate safety level of the trusses. The first three models are defined by a deterministic approach based on the in situ measurements, as: (i) the observed values at different sections; (ii) the mean of the observed values for each element and (iii) the minimum of the values observed for each element. A fourth model assumed the cross section dimensions as random variables, assuming a two-parameter lognormal distribution, with mean value given by the mean of the observed values for each member and $\mathrm{CoV}$ of $10 \%$.

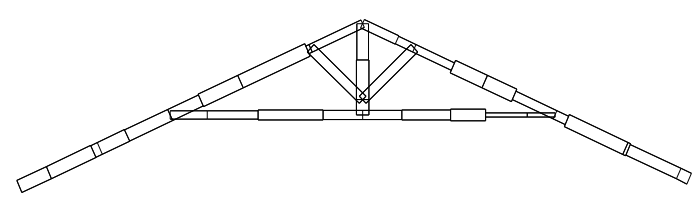

a)

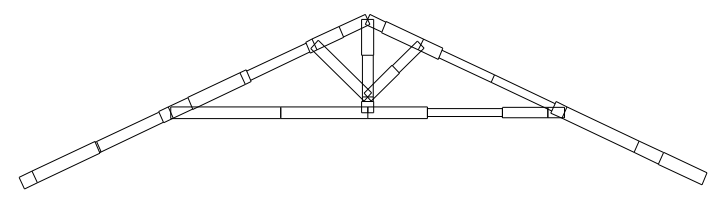

c)

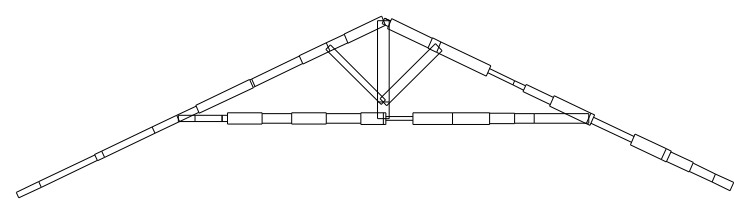

b)

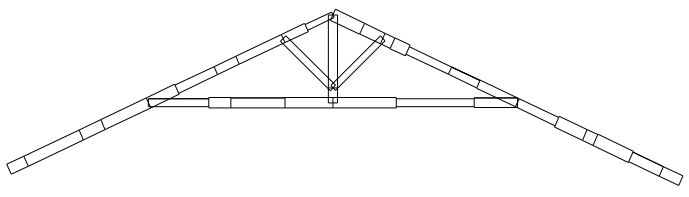

d)

Figure 5: Equivalent cross sections used in the structural models: a) truss \#1; b) truss \#2; c) truss \#3; d) truss \#4.

Dead loads (weight of the trusses, roof tiles and sheeting) were modelled with a normal distribution, with an expected value of $1.5 \mathrm{kN} / \mathrm{m}^{2}$ and a coefficient of variation of $10 \%$. The wind load was calculated considering Eurocode 1 (CEN, 2005) having a value for mean exterior wind pressure of $0.32 \mathrm{kN} / \mathrm{m}^{2}$ for downwind and $0.23 \mathrm{kN} / \mathrm{m}^{2}$ for upwind. The wind action was considered either positive or negative since the trusses do not have a symmetric geometry. Gumbel distributions with coefficient of variation of $20 \%$ were assumed 
for wind speed, since the location and configuration of the building were known, resulting in a wind load with a coefficient of variation of $35 \%$. With respect to the considered actions, three load combinations were assumed. Load combination $P$ considers only the existence of dead load, while combinations $P V 1$ and $P V 2$ considered also the wind load, using respectively Wind 1 and Wind 2, see Figure 6. The considered limit states include section and member ultimate limit states as defined in Eurocode 5 (CEN, 2004). Solid timber and service class 1 were considered to define the $k_{\text {mod }}$ factor, which is equal to 0.6 for combination $P$ and 0.9 for combinations $P V 1$ and $P V 2$.

For assessing structural safety, a Monte Carlo simulation model combined with a linear elastic finite element code was implemented in MATLAB.

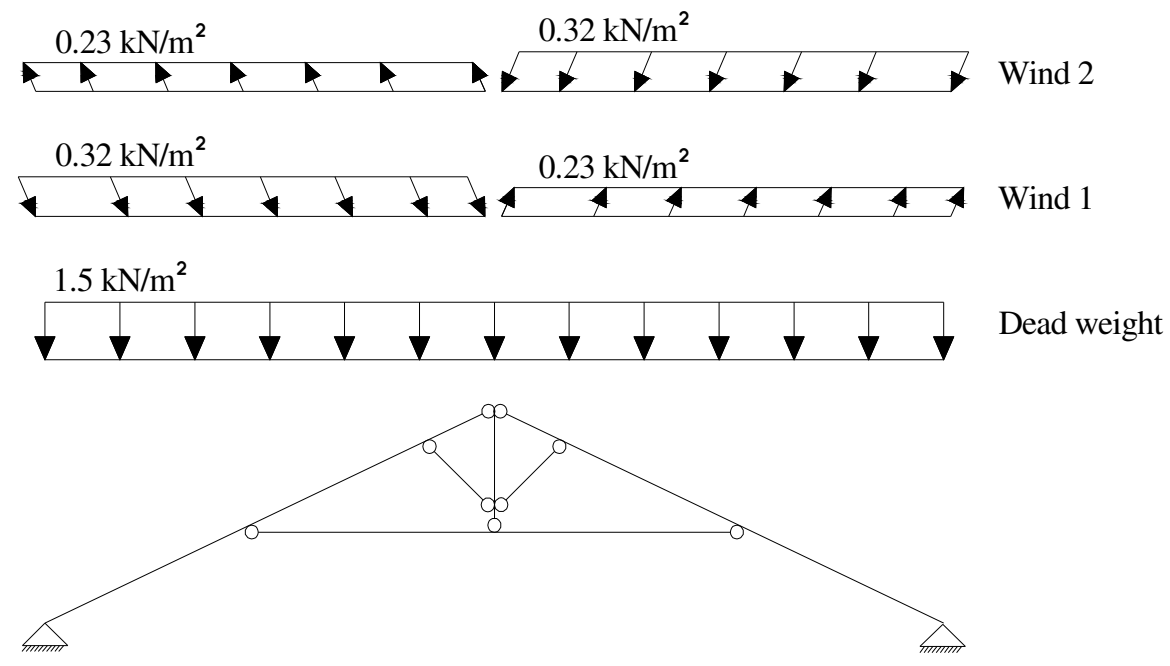

Figure 6: Assumed loads with intensity and direction.

\subsection{Results of cross section models}

As stated before, three geometric models were considered with deterministic cross sections parameters. The first model assumed equivalent cross sections to the residual cross sections found in inspection and aims at simulating the best possible deterministic representation of the geometry, taking into consideration its spatial variation. The cross section for each segment of a member corresponds to the value found in the nearest control section. It is assumed that this is not available in most practical applications, due to obvious costs and time constraints. The cross sections for the second model were defined by the mean value of the inspected values for each member. This scenario would be a typical engineering averaging approach, which somehow incorporates the possibility of stress redistribution along a timber element and reduces the effect of cross sections with small residual area. The last considered deterministic cross section is a worst case scenario, with the cross section for each member being defined by the smallest inspected cross section. This corresponds to the possibility of a brittle behaviour of timber in failure, or a weakest link approach that would be correct if all members would be subjected only to uniaxial loading and alternative load paths could not be found. 
A probabilistic cross section model was also considered for the evaluation of the four timber trusses, assuming the mean value given by the mean of the observed values for each member, plus a coefficient of variation equal to $10 \%$ and a Lognormal distribution. This new model tries to take into account code recommendations for geometric randomness of nondeteriorated structures (JCSS, 2001), as well as the results of in situ measurements of this and other historical timber roof structures.

The reliability index and probability of failure for the timber trusses, regarding each different geometric model, are given in Table 3. For all geometric models, the conditioning failure mode was buckling, as a result of the large slenderness of deteriorated elements. The lower values of reliability are always found for load combination $P$ because a smaller $k_{\text {mod }}$ factor was used on that combination. Trusses \#1 and \#2 have the lower values of reliability index and the models with the inspected values and minimum values for the cross sections indicate that these structures would most likely collapse. The roof structure was still standing before the non-destructive tests were performed, which seems acceptable, mostly because the partly decayed section presents some resistance. In addition, there are also moderate threedimensional effects in the structure and trusses \#2 and \#3 exhibit a lower chord strengthening not considered in the models. Truss \#3 presents, for all geometric models, acceptable values of structural safety even without strengthening and truss \#4 would be only considered unsafe if the minimum values cross section model is used. Here, it is noted that the accepted reliability index for existing structures can be considered equal to 3.3 because the cost of structural interventions is generally high (JCSS, 2000).

If the results obtained with the inspected cross sections are considered as the best possible estimate, then it is clear that the other two approaches provide results far from the real ones. This seems to indicate that there are no simple geometric models providing a good failure estimate for deteriorated timber structures. Still, when looking at all loading combinations, the results indicate that for structures with a low probability of failure (trusses \#3 and \#4) the geometric model with average sections seems to provide better results, and for structures with a very high probability of failure the model with minimum sections seems to provide better results. Of course, the geometric model with minimum sections is always conservative.

The results of the probabilistic cross section model present lower reliability values than those obtained for the deterministic model with mean cross section. This occurs because the new random variable introduces an additional level of uncertainty to the problem. However the behaviour of the geometrical characteristics of the trusses is better defined by the consideration of this probabilistic parameter, since the cross section parameters vary along the elements extension and therefore cannot be assumed merely as deterministic variables. Again, when looking at all loading combinations and comparing with the previous results with a deterministic cross section, the results indicate that for structures with a very low probability of failure (trusses \#3 and \#4) the new model with a probabilistic cross model provides conservative results when compared to the residual sections model, while for structures with a very high probability of failure the new model still provides reasonable results, with probabilities of failure of the same order of magnitude. 
Table 3: Reliability indices and probabilities of failure (in brackets) for cross section geometric models

\begin{tabular}{|c|c|c|c|c|c|}
\hline \multirow{2}{*}{ Truss } & \multirow{2}{*}{$\begin{array}{c}\text { Load } \\
\text { combination }\end{array}$} & \multicolumn{4}{|c|}{ Cross section model } \\
\hline & & inspected values & mean values & minimum values & probabilistic \\
\hline \multirow{6}{*}{1} & \multirow{2}{*}{$P$} & -1.374 & 2.208 & $-\infty$ & 1.281 \\
\hline & & $\left(9.15 \times 10^{-1}\right)$ & $\left(1.36 \times 10^{-2}\right)$ & $(1.00)^{\mathrm{a}}$ & $\left(1.00 \times 10^{-1}\right)$ \\
\hline & \multirow{2}{*}{$P V 1$} & 0.905 & 3.771 & $-\infty$ & 2.671 \\
\hline & & $\left(1.83 \times 10^{-1}\right)$ & $\left(8.12 \times 10^{-5}\right)$ & $(1.00)^{\mathrm{a}}$ & $\left(3.78 \times 10^{-3}\right)$ \\
\hline & \multirow{2}{*}{$P V 2$} & -0.356 & 3.341 & $-\infty$ & 2.307 \\
\hline & & $\left(6.39 \times 10^{-1}\right)$ & $\left(4.18 \times 10^{-4}\right)$ & $(1.00)^{\mathrm{a}}$ & $\left(1.05 \times 10^{-2}\right)$ \\
\hline \multirow{6}{*}{2} & \multirow{2}{*}{$P$} & -2.435 & 1.171 & -2.578 & 0.528 \\
\hline & & $\left(9.93 \times 10^{-1}\right)$ & $\left(1.21 \times 10^{-1}\right)$ & $\left(9.95 \times 10^{-1}\right)$ & $\left(2.99 \times 10^{-1}\right)$ \\
\hline & \multirow[b]{2}{*}{$P V 1$} & -1.231 & 2.238 & -1.348 & 1.359 \\
\hline & & $\left(8.91 \times 10^{-1}\right)$ & $\left(1.26 \times 10^{-2}\right)$ & $\left(9.11 \times 10^{-1}\right)$ & $\left(8.70 \times 10^{-2}\right)$ \\
\hline & \multirow{2}{*}{$P V 2$} & 0.140 & 3.504 & -0.279 & 2.528 \\
\hline & & $\left(4.44 \times 10^{-1}\right)$ & $\left(2.30 \times 10^{-4}\right)$ & $\left(6.10 \times 10^{-1}\right)$ & $\left(5.74 \times 10^{-3}\right)$ \\
\hline \multirow{6}{*}{3} & \multirow{2}{*}{$P$} & 3.917 & 5.186 & 3.284 & 3.641 \\
\hline & & $\left(4.48 \times 10^{-5}\right)$ & $\left(1.07 \times 10^{-7}\right)$ & $\left(5.12 \times 10^{-4}\right)$ & $\left(1.36 \times 10^{-4}\right)$ \\
\hline & \multirow{2}{*}{$P V 1$} & 5.962 & 6.509 & 5.091 & 4.785 \\
\hline & & $\left(1.25 \times 10^{-9}\right)$ & $\left(3.78 \times 10^{-11}\right)$ & $\left(1.79 \times 10^{-7}\right)$ & $\left(8.55 \times 10^{-7}\right)$ \\
\hline & \multirow{2}{*}{$P V 2$} & 5.039 & 6.032 & 4.341 & 4.466 \\
\hline & & $\left(2.35 \times 10^{-7}\right)$ & $\left(8.08 \times 10^{-10}\right)$ & $\left(7.08 \times 10^{-6}\right)$ & $\left(3.98 \times 10^{-6}\right)$ \\
\hline \multirow{6}{*}{4} & \multirow[b]{2}{*}{$P$} & 4.184 & 3.985 & -2.808 & 2.774 \\
\hline & & $\left(1.43 \times 10^{-5}\right)$ & $\left(3.37 \times 10^{-5}\right)$ & $\left(9.98 \times 10^{-1}\right)$ & $\left(2.77 \times 10^{-3}\right)$ \\
\hline & \multirow{2}{*}{$P V 1$} & 4.942 & 4.768 & -1.200 & 3.752 \\
\hline & & $\left(3.86 \times 10^{-7}\right)$ & $\left(9.30 \times 10^{-7}\right)$ & $\left(8.85 \times 10^{-1}\right)$ & $\left(8.76 \times 10^{-5}\right)$ \\
\hline & \multirow{2}{*}{$P V 2$} & 7.066 & 5.605 & -0.291 & 3.999 \\
\hline & & $\left(7.97 \times 10^{-13}\right)$ & $\left(1.04 \times 10^{-8}\right)$ & $\left(6.14 \times 10^{-1}\right)$ & $\left(3.18 \times 10^{-5}\right)$ \\
\hline
\end{tabular}

${ }^{\mathrm{a}}$ In all simulations, the limit state function is violated

\subsection{Residual cross section variation}

The assumption that the cross section area deteriorated by biological agents had no contribution to structural resistance proved too conservative, particularly when studying the two most affected trusses (trusses \#1 and \#2). Therefore, a new analysis was carried out where the deteriorated area was assumed to partly contribute to the resistance of the cross section. A remaining capacity factor, $\alpha$, was considered such that the final residual cross section area can be defined as:

$$
A_{f}=A_{N D}+\alpha \cdot A_{D}
$$

where $A_{f}$ is the assumed corrected residual cross section for each element, $A_{N D}$ is the area which was not attacked by neither xylophagous insects nor wood-destroying fungi, $A_{D}$ is the 
area which was attacked by a deteriorating agent and $\alpha$ is the remaining capacity factor, which is assumed to take any value between 0 and 0.5 .

The model considered is the deterministic cross section model with inspected values for the cross sections, with the updated new larger residual cross sections. The evolution of the reliability index in terms of the remaining capacity factor, for each truss, is shown in Figure 7. As shown by the slope of the diagrams, coefficient $\alpha$ has a larger influence for more decayed trusses (trusses \#1 and \#2) since the ratio $A_{D} / A_{N D}$ is larger. Taking into account that the timber trusses were standing when the inspection was conducted, and that the threedimensional effects are typically small in this type of structures and usually neglected in the safety assessment, it is acceptable to assume that the reliability indices of the most deteriorated timber structures are, at least, equal to zero. This means that a value $\alpha$ between $5 \%$ (for truss \#1) and 25\% (for truss \#2) should be used on the evaluation of the safety of existing timber structures. As truss \#2 was actually strengthened with a lower chord, a conservatively low value of $10 \%$ can be possibly suggested.

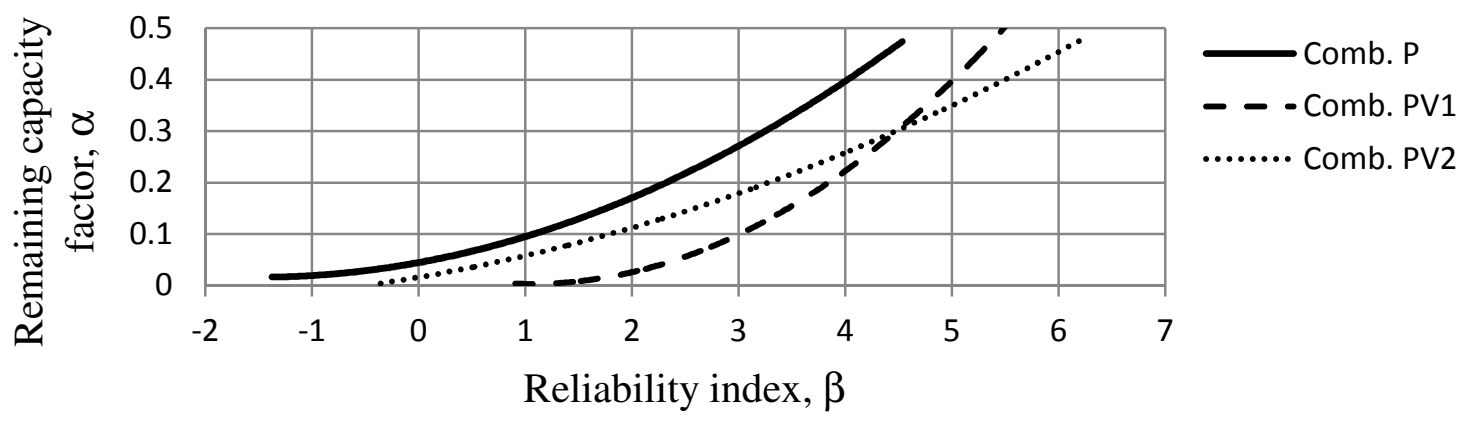

a)

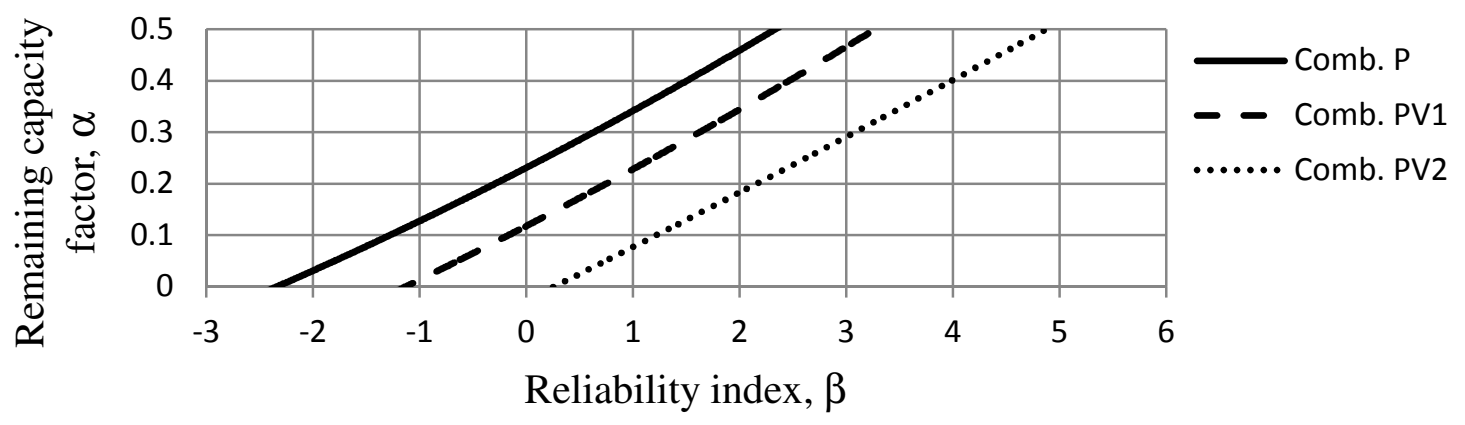

b)

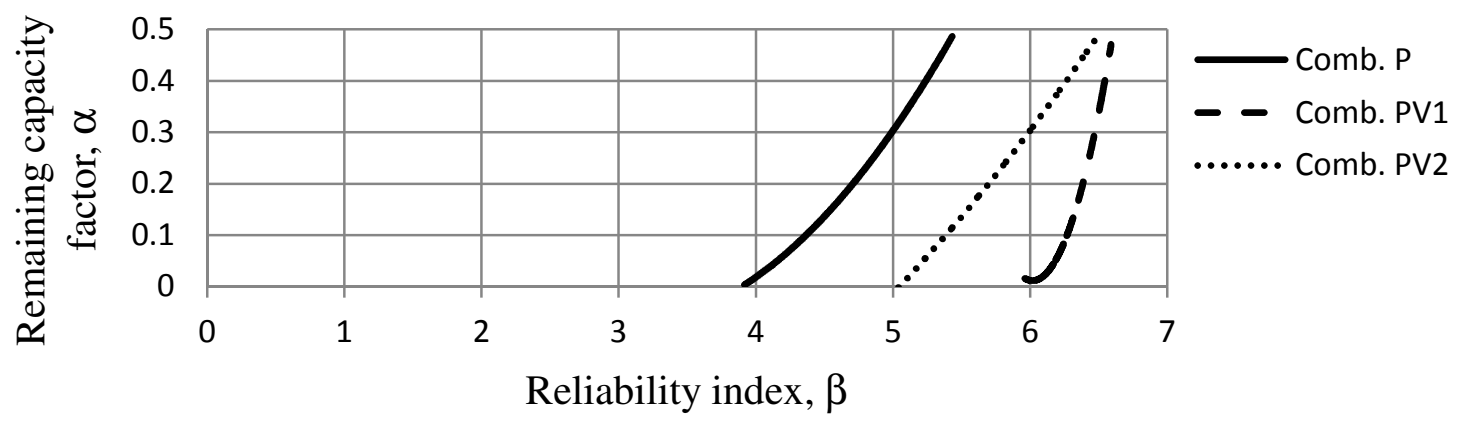




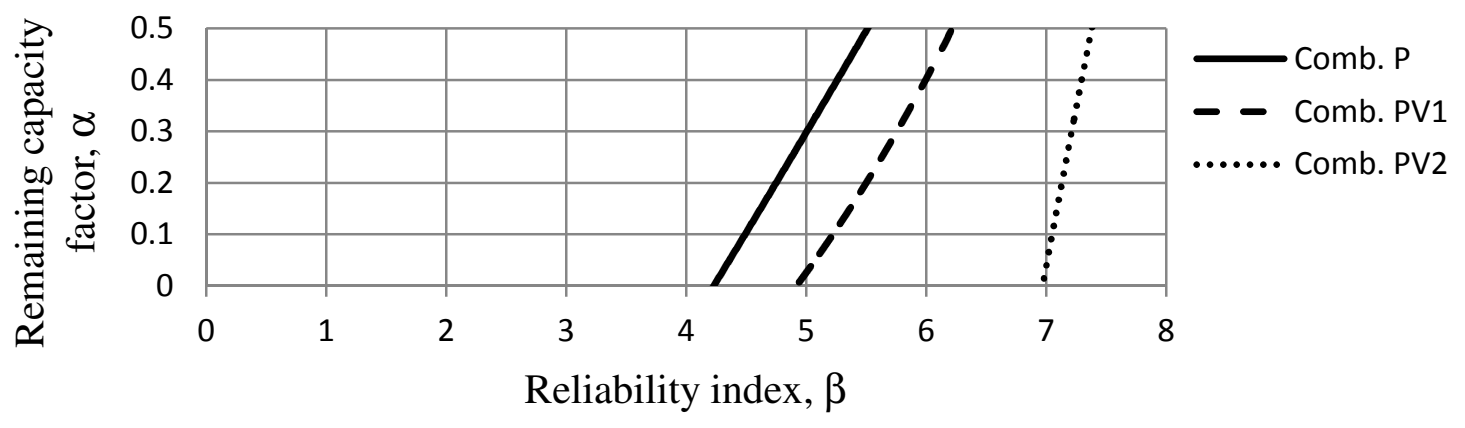

d)

Figure 7: Evolution of $\beta$ with remaining capacity factor, $\alpha$ : a) truss \#1; b) truss \#2; c) truss \#3; d) truss \#4

\subsection{Time evolution deterioration curves}

Finally, a decay model was considered to study how the reliability indices might have evolved during the trusses lifespan. The decay was defined by an idealized model with two parameters (Leicester, 2001): the time of incubation or the time between the installation of the timber element and the point that noticeable decay commences, $t_{\text {lag }}$ (year), and an annual decay rate, $r$ (mm/year) (Figure 8). According to Wang et al. (2006), the parameters may be given by:

$$
\begin{aligned}
& r=k_{\text {wood }} \cdot k_{\text {climate }} \\
& t_{\text {lag }}=3 \cdot r^{-0.4}
\end{aligned}
$$

where $k_{\text {wood }}$ depends on the timber durability class and $k_{\text {climate }}$ depends on climatic factors. Considering a probabilistic analysis, the $t_{l a g}$ parameter is to be defined as a deterministic variable, while the $r$ parameter should be defined by a lognormal distribution with a coefficient of variation between 0.5 and 1 according to the timber durability class (Wang et al, 2006).

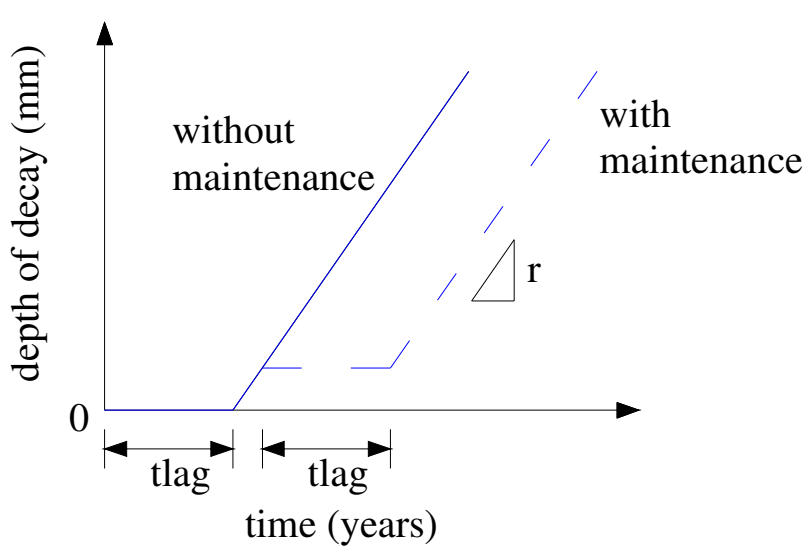

a)

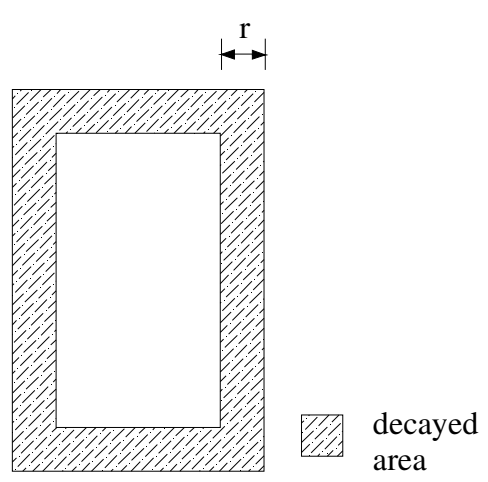

b)

Figure 8: Progress of decay: a) idealized model, adapted from Leicester (2001); b) damage penetration on a decayed cross section 
With respect to the geometrical survey, the initial cross sections without deterioration were used and the safety level of the timber trusses was first estimated. This means that reliability values were computed for both the original non-deteriorated structure and existing structure at the time of inspection. Those two dates have about 230 years difference. Since the reliability values and the geometry of the cross sections can be estimated for two specific periods of the trusses age, the decay parameters could be determined. Subsequently, different annual decay rates were assumed iteratively so that, starting with the initial cross sections and having a 230 years decay process, the reliability indices would correspond to the safety level obtained in the date of inspection. After defining these parameters, it was possible to estimate the time evolution deterioration curves for the most decayed truss (truss \#2), as shown in Figure 9 for the models with probabilistic cross section and inspected cross section values with contribution of the decayed area $(\alpha=0.25)$. In both models, only the load combination $P$ was analyzed since it corresponds to the critical load combination. The decay rates were similar for both models, with $0.07 \mathrm{~mm} /$ year for the probabilistic model and $0.08 \mathrm{~mm} / \mathrm{year}$ for the model that considered a $\alpha=0.25$ ( $t_{\text {lag }}$ of 8.7 and 8.2 years, respectively).

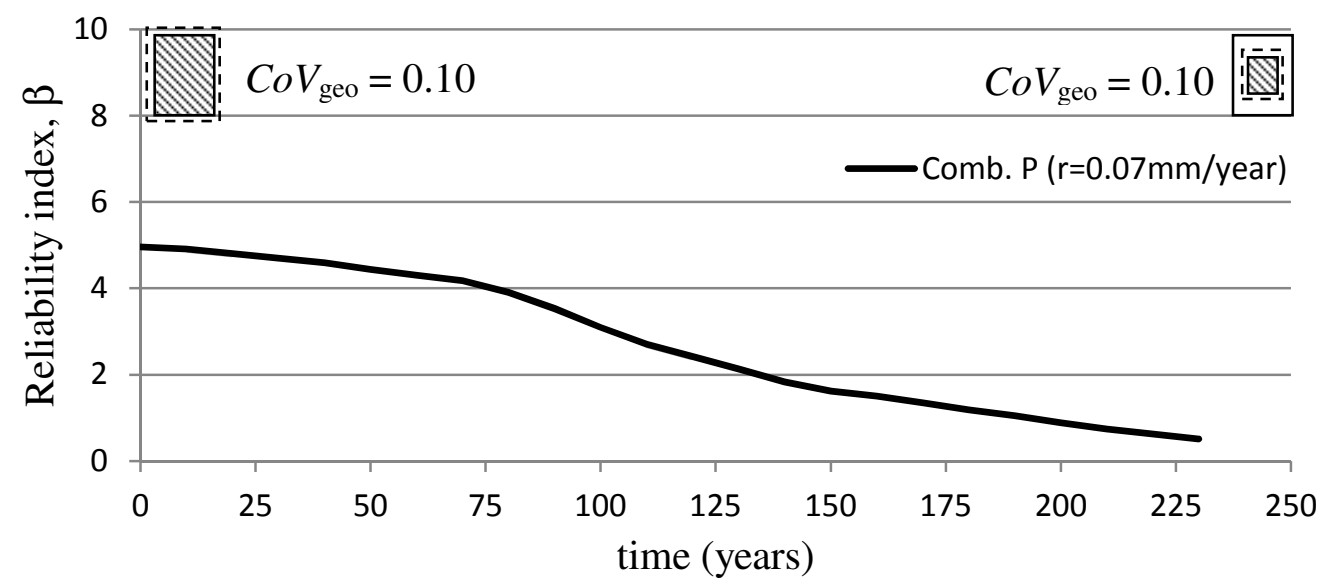

a)

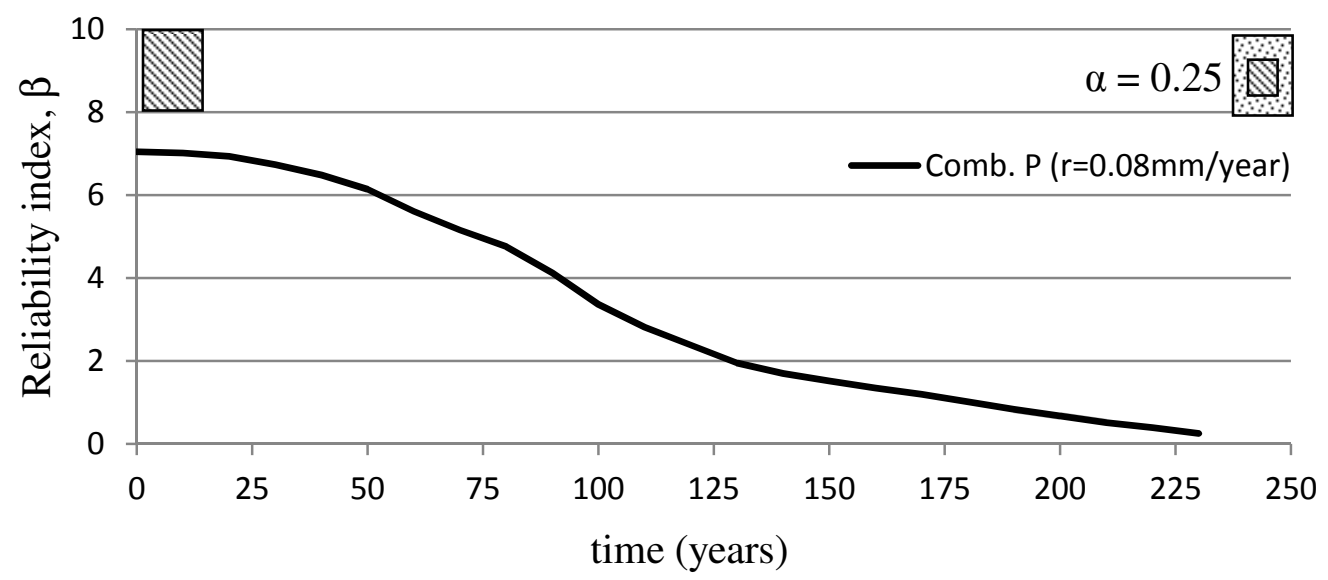

b)

Figure 9: Time evolution deterioration curves for truss \#2 using models with: a) probabilistic cross section; b) residual cross section variation, $\alpha=25 \%$. 
The reliability index evolution presents three different stages in both models. The first stage corresponds to the initial life phase of the truss, presenting high and almost constant over time reliability indices, due to the influence of $t_{\text {lag. }}$. The second stage is associated with a significant decrease of the reliability indices as the decay evolution leads to the violation of the considered limit states equations. The last stage represents a less significant decrease of the reliability indices since, at this time, the decay process is fully developed and the subsequent probabilities of failure are already very large. Although the initial reliability indices are different, the time evolution curves present similar results after 100 years.

Taking into consideration the obtained time dependent curves and considering the suggested minimum reliability indices (CEN, 2002 and JCSS, 2000), it would be possible to define maintenance, repairing or strengthening actions so that the lifetime of the structure could be extended with adequate safety conditions. With these two models, an intervention should be executed after 95 years in order to maintain a reliability index of 3.3.

\section{CONCLUSIONS}

Reliability methods can be applied to existing timber structures, not only to assess the structural safety, but also to evaluate life-cycle performance, allowing a more accurate estimation of future maintenance needs. This work presents a framework for both safety assessment and life-cycle analysis of existing timber structures, with particular emphasis on models for the geometric properties of decayed timber elements.

A survey carried out on existing timber structures older than 70 years provided estimates of the probabilistic indicators of cross section geometry of timber structures. For rectangular shape and low biological deterioration a coefficient of variation lower than $10 \%$ was found, whereas for round shapes a value lower than $20 \%$ can be used. In the case of highly deteriorated cross sections, values up to $40 \%$ were found.

Using a case study and a detailed inspection of a highly deteriorated structure, different geometric models, both deterministic and probabilistic were considered in order to assess the structural safety. The obtained results indicate that modelling the cross section geometry considering a probabilistic model with mean cross sections equal to the results from inspection and a coefficient of variation of $10 \%$ (JCSS, 2001) results in reasonable estimates of safety. It was also concluded that assuming all deteriorated timber as non resistant leads to erroneous results, and a remaining capacity factor for the residual cross section area of $10 \%$ provides significantly more consistent results.

Finally, the proposed model was used to define time evolution deterioration curves, resulting in a prediction of time-dependent reliability index over the life-cycle. The model defines an initial incubation period of the deterioration process followed by a constant annual decay rate. For the Portuguese environmental conditions, considering softwood, the following values were obtained for the decay model: annual decay rate of $0.075 \mathrm{~mm} / \mathrm{year}$ and time of incubation of approximately 8.5 years. In this case, a repair and strengthening intervention should have been carried out 95 years after construction in order to maintain adequate safety levels. 


\section{ACKNOWLEDGMENTS}

The financial support of the Portuguese Science Foundation (Fundação de Ciência e Tecnologia), through project PTDC/ECM/66527/2006 and PhD grants SFRH/BD/27353/2006 and SFRH/BD/62326/2009, is gratefully acknowledged.

\section{REFERENCES}

Brites RD (2011) Safety assessment of ancient timber structures. PhD Thesis, University of Minho.

CEN (2002) EN 1990:2002 - Basis of Structural Design. European Committee for Standardization (CEN). Brussels.

CEN (2004) EN 1995-1-1:2004 - Eurocode 5 - Design of Timber Structures - Part 1-1: General - Common rules and rules for buildings. European Committee for Standardization (CEN). Brussels.

CEN (2005) EN 1991-1-4:2005 - Eurocode 1 - Actions on structures - Part 1-4: General actions - Wind actions. European Committee for Standardization (CEN). Brussels.

Frangopol DM, Kong JS, Gharaibeh ES (2001) Reliability-based life-cycle management of highway bridges. Journal of Computing in Civil Engineering 15(1):27-34.

Frangopol DM, Lin KY, Estes AC (1997) Life-cycle cost design of deteriorating structures. Journal of Structural Engineering 123(10): 1390-1401.

Feio A, Lourenço PB, Machado JS (2007) New and old chestnut wood parallel to the grain: Mechanical behaviour and non-destructive evaluation. International Journal of Architectural Heritage 1(3):272-292.

Görlacher R (1987) Non destructive testing of wood: an in-situ method for determination of density. Holz as Roh- und Werkstoff 45(7):273-278.

IPQ (1995) NP 4305. Sawn wood from maritime pine for structures - visual grading (in Portuguese).

Joint Committee on Structural Safety (2000) JCSS Probabilistic Model Code, Part I: Basis of Design. Probabilistic Model Code.

Joint Committee on Structural Safety (2001) JCSS Probabilistic Model Code, Part II: Load Models. Probabilistic Model Code.

Joint Committee on Structural Safety (2006) JCSS Probabilistic Model Code, Part III: Resistance Models - 3.5 Properties of Timber. Probabilistic Model Code.

Kessel MH, Sandoz JL (1989) The efficiency of timber grading. Holz als Roh- und Werstoff 47(7):279-284.

Köhler J (2007) Reliability of timber structures. PhD Thesis, Institute of Structural Engineering, Swiss Federal Institute of Technology.

Köhler J, Sørensen J, Faber M (2007) Probabilistic modelling of timber structures. Structural Safety 29(4):255-267.

Kong JS, Frangopol DM (2002) Life-cycle performance prediction of steel/concrete composite bridges. International Journal of Steel Structures 2(1):13-19. 
Leicester RH (2001) Engineered durability for timber construction. Progress in Structural Engineering and Materials 3(3):216-227.

Lourenço PB, Feio A, Machado JS (2007) Chestnut wood in compression perpendicular to the grain: Non-destructive correlations for new and old wood. Construction and Building Materials 21(8):1617-1627.

Neves LC, Frangopol DM (2005) Condition, safety, and cost profiles for deteriorating structures with emphasis on bridges. Reliability Engineering \& System Safety 89(2): 185-198.

Nowak AS, Park CH, Szerszen MM (1998) Lifetime reliability profiles for steel girder bridges. In: Frangopol DM, (ed), Optimal Performance of Civil Infrastructure Systems. ASCE, Reston, Virginia. 139-154.

Pettigrew TM, Fragiacomo M, Bull DK (2006) Verification of raker shores using New Zealand timber. Proceedings of the 2006 New Zealand Society for Earthquake Engineering Conference, Napier, New Zealand.

Pinto-Lopes J (1950) Polyporoses and fungi causing decomposition of wood in Portugal. Rev. Fac. Cienc. Lisb. 100(1): 53-108.

Ranta-Maunus A (2004) Theoretical and Practical Aspects of the Reliability Analysis of Timber Structures. WCTE 2004 Conference, Lahti, Finland.

Rinn F, Schweingruber F (1996) Resistograph and X-ray density charts of wood comparative evaluation of drill resistance profiles and X-ray density charts of different wood species. International Journal of the Biology, Chemistry, Physics and Technology of Wood 50(4):303-311.

Sandoz JL (1991) Non-destructive Evaluation for Building Timber. Visual and Ultrasound Grading. Timber Eng. Conf. London, UK.

Smith I (1982) Failure criteria for timber subjected to complex stress state due to short term loading. Research report 3/82, Timber Research and Development Association. High Wycombe, UK.

Sørensen JD, Svensson S, Stang BD (2005) Reliability-based calibration of load duration factors for timber structures. Structural Safety 27(2):153-169.

Teles CDM, Valle A (2001) Wood structures: Acting before deterioration. Historical Constructions, P.B. Lourenço, P. Roca (Eds), Guimarães, Portugal: 857-866.

Thoft-Christensen $\mathrm{P}$ (1998) Assessment of the reliability profiles for concrete bridges. Engineering Structures 20(11):1004-1009.

UNI (2004). UNI 11119:2004 - Cultural Heritage, Wooden artefacts, Load-bearing structures, On site inspections for the diagnosis of timber members. UNI Milano

Valle A, Brites RD, Lourenço PB (2005) Survey of the degradation conditions of the roof trusses in Chimico laboratory - A1, Coimbra. Civil Engineering Department of the University of Minho, Guimarães, Portugal (in Portuguese).

Wang C, Leicester RH, Nguyen M (2006) Probabilistic procedure for design of untreated timber poles in-ground under attack of decay fungi. Reliability Engineering \& System Safety 93(3):476-481. 